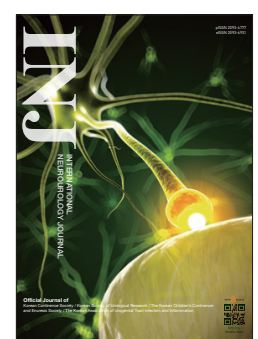

\section{Editorial}

Int Neurourol J 2018;22 Suppl 3:S104-105

https://doi.org/10.5213/inj.1820edi.008

pISSN 2093-4777 • eISSN 2093-6931

\title{
Up to Date on Astrocytes
}

\author{
Jin Wook Kim (iD https://orcid.org/0000-0003-4157-9365 \\ Department of Urology, Chung-Ang University College of Medicine, Seoul, Korea \\ E-mail: jinwook.kim.md@gmail.com
}

This issue of the International Neurourology Journal (INJ) leaves the comfort of the periphery to the relatively daunting reaches of the central nervous system (CNS). The central themes of the collection of these articles, 2 original papers and 1 review, is the glial activity in regulating plasticity, or conversely its failure as evident in senescence.

The laymen of these disciplines will be able to find her footing to check out the review by Hussaini and Jang, as they cover the recent rediscovery of astrocytes and its role in CNS plasticity [1]. The role of the astrocyte has recently been redefined, as what had formerly been considered 'simply structural' has show to have a vast spectrum of regulatory activity. Astrocytes, being localized near blood vessels, are in an optimum position to regulate distribution of nutrients and molecules to neurons. Astrocyte networks ensheathes synapse, permitting supplies of energy substrates, providing structural support, and modulating synaptic plasticity [2,3]. Recent emergent concepts suggest a 'tripartite' synaptic organization, with astrocytes mediating between the pre- and postsynaptic neuron [2]. Besides regulating cleft concentration and limiting diffusion of neurotransmitters, sensors at the glial membranes trigger activation of a broad range of intracellular messengers, including calcium waves [4]. Active substances released from glial cells modulate synaptic strength, promoting insertion of AMPA ( $\alpha$-amino-3-hydroxy-5-methyl-4isoxazolepropionic acid) receptors at the surface of post synaptic neurons [5]. The involvement of astrocytes in synaptic energy metabolism naturally leads to its functional implication, memory. Astrocytes serve a primary role in inducing long-term potentiation, as a regulator of glutamate. Its various roles in principal neurologic diseases are also touched upon in this review.

Not unrelated, Cho et al. [6], presents an article describing BubR1 and the neurobehavioral impact of its knockout. BubR1 was first described as an inhibitor of the anaphase-promoting complex that triggers the transition from metaphase to anaphase by targeting cell cycle regulators for degradation [7]. Whether it is the cell cycle role of BubR1 that regulates lifespan is not known, yet in mice levels of BubR1 significantly decline with age. BubR1 hypomorphic mice that constitutively express low levels of BubR1 are normal in appearance and size at birth, but undergo slow postnatal growth and have a shortened lifespan exhibiting premature aging phenotypes [8]. Naturally a target of senescence, previous studies by this group has demonstrated BubR1 insufficiency resulting in impaired hippocampal neurogenesis and myelination $[9,10]$. In this study, hippocampal functions are demonstrated through elevated plus maze and the light-dark test, tail-suspension and forced-swim test and novel object recognition to test for anxiety, depression and memory-related functions. All results consistently showed impairment with hypomorphic allele BubR1 and knockdown mice.

In another article, also presenting investigations into chronic neurodegenerative functions, Lee et al. [11] utilizes rotenone based Parkinson disease model to show treadmill exercises helps prevent motor function deterioration through suppression of Purkinje cell loss. The cerebellum is important brain area in motor coordination and balance and it has been recognized as a prominent contributor to a wide array of cognitive and emotional functions. Neuroglial cells, such as astrocytes and microglia, play modulate neuronal function and homeostasis. However, 
during reactive astrocytes and microglial activation secondary to injury or in response to neuronal dysfunction, several factors that evoke inflammatory responses are secreted [12]. Therefore, reactive astrocytes and microglia activation induce neuronal and synaptic changes that are likely to contribute to CNS dysfunction during disease processes [13]. Purkinje cells are typically injured through a variety of toxic and neurodegenerative causes, and loss of Purkinje cells is closely related to reactive astrogliosis. The activity of treadmill exercise showing direct implication in the pathophysiology of cerebellar senescence is demonstrated in these pages.

- Conflict of Interest: No potential conflict of interest relevant to this article was reported.

\section{REFERENCES}

1. Hussaini SM, Jang MH. New roles for old glue: astrocyte function in synaptic plasticity and neurological disorders. Int Neurourol J 2018;22(Suppl 3):S106-14.

2. Halassa MM, Fellin T, Haydon PG. The tripartite synapse: roles for gliotransmission in health and disease. Trends Mol Med 2007;13:5463.

3. Almad A, Maragakis NJ. A stocked toolbox for understanding the role of astrocytes in disease. Nat Rev Neurol 2018;14:351-62.

4. Volterra A, Liaudet N, Savtchouk I. Astrocyte $\mathrm{Ca}^{2+}$ signalling: an unexpected complexity. Nat Rev Neurosci 2014;15:327-35.

5. Tasker JG, Oliet SH, Bains JS, Brown CH, Stern JE. Glial regulation of neuronal function: from synapse to systems physiology. J Neuroendocrinol 2012;24:566-76.

6. Cho CH, Yang Z, Yoo KH, Oliveros A, Jang MH. BubR1 insufficiency impairs affective behavior and memory function in mice. Int Neurourol J 2018;22(Suppl 3):S122-30.

7. Elowe S. Bub1 and BubR1: at the interface between chromosome attachment and the spindle checkpoint. Mol Cell Biol 2011;31:3085-93.

8. Baker DJ, Jeganathan KB, Cameron JD, Thompson M, Juneja S, Kopecka A, et al. BubR1 insufficiency causes early onset of aging-associated phenotypes and infertility in mice. Nat Genet 2004;36:744-9.

9. Choi CI, Yoo KH, Hussaini SM, Jeon BT, Welby J, Gan H, et al. The progeroid gene BubR1 regulates axon myelination and motor function. Aging (Albany NY) 2016;8:2667-88.

10. Yang Z, Jun H, Choi CI, Yoo KH, Cho CH, Hussaini SM, et al. Age-related decline in BubR1 impairs adult hippocampal neurogenesis. Aging Cell 2017;16:598-601.

11.Lee JM, Kim TW, Park SS, Han JH, Shin MS, Lim BV, et al. Treadmill exercise improves motor function by suppressing Purkinje cell loss in Parkinson disease rats. Int Neurourol J 2018;22(Suppl 3):S147-55.

12. Ben Haim L, Rowitch DH. Functional diversity of astrocytes in neural circuit regulation. Nat Rev Neurosci 2017;18:31-41.

13. Khakh BS, Sofroniew MV. Diversity of astrocyte functions and phenotypes in neural circuits. Nat Neurosci 2015;18:942-52. 